\title{
Variabilidade produtiva e agrupamentos de colheitas de abobrinha italiana cultivada em ambiente protegido
}

\author{
Productive variability and crop groupings of zucchini cultivated in protected environment
}

\author{
Ricardo Howes Carpes ${ }^{\mathrm{I}}$ Alessandro Dal'Col Lúcio ${ }^{\mathrm{II} *}$ Sidinei José Lopes ${ }^{\mathrm{II}}$ Vilson Benz ${ }^{\mathrm{III}}$ \\ Fernando Haesbaert ${ }^{\mathrm{III}}$ Daniel Santos ${ }^{\mathrm{III}}$
}

\section{RESUMO}

No planejamento experimental, a variabilidade entre parcelas pode alterar as estimativas dos tamanhos de parcela e de amostra, além do número de repetições e definição do delineamento experimental. Para verificar a interferência da variabilidade das estimativas de valores usados na determinação do tamanho de parcelas com diferentes números de plantas e agrupamentos de colheitas, realizou-se um trabalho com dois experimentos. Um experimento foi realizado no inverno/na primavera de 2004, e outro, no verão/outono de 2005 com a cultura da abobrinha italiana. As plantas foram cultivadas em túnel plástico, com irrigação por gotejamento, com três linhas de cultivo, 24 plantas por linha e espaçamento entre plantas de 0,8m e entre filas de 1,2m. Cada planta foi considerada como a unidade básica (UB) do tamanho da parcela. A sequência de duas, três ou quatro plantas na linha de cultivo formou as parcelas $(X)$. Foram realizadas análises considerando-se apenas colheitas individuais e colheitas agrupadas. Para cada experimento, foram obtidas as estimativas da variância, do coeficiente de variação e do índice de informação relativa. Aplicou-se o teste de Bartlett entre as variâncias das colheitas individuais e agrupadas em cada tamanho de parcela simulado. Foram verificados acréscimos nas estimativas da variância da fitomassa de frutos com o aumento do tamanho da parcela e/ou do número de colheitas agrupadas. As variâncias entre as colheitas agrupadas foram homogêneas a partir do agrupamento de três colheitas. O índice de informação relativa apresentou valores próximos a $100 \%$ com os agrupamentos de colheitas. O arranjo de quatro grupos de colheitas agrupadas, combinado com parcelas de quatro plantas, reduz a variabilidade entre parcelas.

Palavras-chave: Cucurbita pepo, olericultura, precisão experimental, tamanho de parcela.

\begin{abstract}
In the experimental planning the variability among portions can alter the estimates of the plot sizes and of sample, besides the number of repetitions and definition of the experimental designs. To verify the variability interference of the estimates of values used to determinate the plot size with different numbers of plants and groupings of crops, a twoexperiment work was carried out. The first trial was carried with zucchini in winter/spring of 2004 and the second in the summer/ autumn of 2005. The plants were cultivated in plastic tunnel, with drip irrigation with three lines with 24 plants per row, spacing among plants $0.8 \mathrm{~m}$ and among lines $1.2 \mathrm{~m}$. Each plant was considered as a basic unit (UB) of the plot size. The sequence of two, three and four plants in the crop row formed the plots of two, three and four UB of size (X). Analyses were accomplished considering only considered individual and combined harvests. In both experiments, the estimative of variance, variation coefficient and relative information index were obtained. Bartlett's test was applied among the variances of the individual and combined harvests in each size of simulated plot. There were some increases in the estimative in the variance of fruits biomass with the increase of the plot size and/or the number of grouped harvests. The variances, among the grouped harvests, were homogeneous, considering the grouping of three harvests. The relative information index and the relative coefficient present values close to $100 \%$ with the groupings of crops. The arrangement of four groups of combined harvests, joined with plots of four plants for zucchini reduce the variability among plots.
\end{abstract}

Key words: Cucurbita pepo, horticulture, experimental precision, plot size.

'Programa de Pós-graduação em Agronomia, Centro de Ciências Rurais (CCR), Universidade Federal de Santa Maria (UFSM), Santa Maria, RS, Brasil.

"Departamento de Fitotecnia, CCR, UFSM, 97105-900, Santa Maria, RS, Brasil. E-mail: adlucio@smail.ufsm.br. *Autor para correspondência.






\section{INTRODUÇÃO}

A abobrinha italiana (Curcubita pepo) é uma das 10 hortaliças de maior valor econômico e de maior produção no Brasil, principalmente no centro e sul do país. Tem ciclo de 50 a 80 dias, podendo ser cultivada em campo, tanto no verão, quanto na primavera (CAMARGO, 1981). Em cultivo protegido, além desses períodos, pode ser produzida no outono e inverno, quando o preço por quilo pode triplicar. $\mathrm{O}$ sistema predominante de cultivo de hortaliças é o convencional; porém, nos últimos anos, tem-se verificado significativo crescimento no cultivo em ambiente protegido, principalmente pela maximização da produção, pela obtenção de produtos de alta qualidade, pela maior precocidade, pelo controle de pragas e doenças com maior facilidade e pela economia da água de irrigação (CERMEÑO, 1990). Além disso, LORENTZ et al. (2004) relatam que esse sistema permite o cultivo de hortaliças fora da época preferencial e em locais onde as condições de cultivo são limitantes.

No planejamento experimental, as definições do tamanho e da forma de parcela, do número de repetições, do tamanho da amostra, do delineamento experimental, dentre outras características, são diretamente influenciadas pela variabilidade inerente ao experimento (STEEL et al., 1997; STORCK et al., 2006). Essa variabilidade, segundo STORCK et al. (2006), também interfere no momento da análise dos resultados, inflacionando a estimativa do erro experimental e levando o pesquisador a interpretações e conclusões com baixa precisão experimental e confiabilidade.

Em cultivos de olericolas em ambiente protegido, como estufas e túneis plásticos, fatores como a proximidade das linhas de cultivo com as laterais da estufa, a presença ou ausência de frutos aptos a serem colhidos em determinada colheita, as múltiplas colheitas realizadas para algumas culturas e o manejo cultural mais intensivo são, de acordo com LORENTZ et al. (2005) e LÚCIO et al. (2008), algumas fontes de variabilidade no sistema de cultivo que devem ser controladas durante a execução de experimentos, evitando assim inflacionar o erro experimental.

Trabalhando no sentido de identificar as interferências das fontes de variabilidade presentes no sistema de cultivo em ambiente protegido, sob as diversas estimativas no planejamento de experimentos, autores como LOPES et al. (1998), MARODIM et al. (2000), SOUZA et al.(2002), MELLO et al. (2004), LÚCIO et al. (2004), LORENTZ et al. (2005), LÚCIO et al. (2006), FEIJÓ et al. (2008), LÚCIO et al. (2008) e CARPES et al. (2008) apontaram que existe variabilidade significativa entre as linhas de cultivo e entre épocas de colheita, independentemente da cultura olerícola avaliada, e que essa variabilidade altera de forma significativa as estimativas dos tamanhos de amostra, do tipo de amostragem, do tamanho e da forma de parcela, do delineamento experimental e do número de colheitas suficientes para correta discriminação entre os tratamentos estudados.

Com essas características inerentes ao sistema de cultivo de olerícolas em ambiente protegido, há então a necessidade de caracterizar as fontes de variabilidade existentes nessa condição de cultivo e planejar o experimento de tal forma a mantê-las sob controle. Como várias culturas olerícolas, a abobrinha italiana tem os frutos colhidos em diferentes períodos de tempo, assim, algumas plantas podem não apresentar frutos aptos a serem colhidos em determinado momento, ficando com produção nula. Essa produção gera dentro do banco de dados observações com valores nulos, inflacionando a variância do experimento. Uma das hipóteses para minimizar os efeitos desse problema é trabalhar com parcelas com número maior de plantas e/ou agrupar colheitas sucessivas, favorecendo a redução de parcelas com valores nulos de produção em colheitas específicas e, dessa forma, reduzindo a variabilidade entre linhas de cultivo, entre parcelas dentro da mesma linha e entre colheitas realizadas.

Assim, o presente trabalho teve como objetivo estudar a variabilidade da produção de frutos de abobrinha italiana com simulações de diferentes números de plantas por parcela e agrupamentos de colheitas.

\section{MATERIAL E MÉTODOS}

Os experimentos com abobrinha italiana, cultivar 'Caserta', foram conduzidos nas estações de inverno/primavera (I/P) de 2004 e verão/outono (V/O) de 2005, no Departamento de Fitotecnia da Universidade Federal de Santa Maria, com latitude de 29॰43’28.23”'S, longitude de 5343'17.22”'O e altitude de $104 \mathrm{~m}$, sendo o clima classificado como Cfa (subtropical úmido sem estação seca definida e com verões quentes) e solo classificado como Argissolo Vermelho distrófico arênico (EMBRAPA, 1999). Em cada estação, o cultivo foi realizado em túnel plástico com dimensões de 3,5m de altura na parte central, $25 \mathrm{~m}$ de comprimento por $4 \mathrm{~m}$ de largura, com área útil de 19,2m de comprimento e 3,6m de largura, coberto com filme de Polietileno de Baixa Densidade (PEBD) de 200 micras, utilizando irrigação por gotejamento. Os camalhões com $0,15 \mathrm{~m}$ de altura e $0,4 \mathrm{~m}$ de largura foram cobertos com 
mulching preto de PEDB de 35 micras de espessura, formando três linhas de cultivo, com 24 plantas por linha, espaçamento entre plantas de $0,8 \mathrm{~m}$ e entre linhas de cultivo $1,2 \mathrm{~m}$. Todos os tratos culturais foram realizados com base na recomendação para a cultura, de acordo com FILGUEIRA (2000).

As unidades básicas (UB) foram compostas por uma planta, resultando em 24UB por linha. Os frutos foram colhidos quando apresentavam tamanho de 15 a $20 \mathrm{~cm}$, com determinação da fitomassa fresca usando balança digital com resolução de um grama. Foram realizadas 12 e 10 colheitas, totalizando um período de colheita de 23 e 27 dias, respectivamente, nos anos de 2004 e 2005. A sequência de duas, três e quatro plantas na linha formou as parcelas de duas, três e quatro UB de tamanho $(\mathrm{X})$. O número de repetições de cada tamanho de parcela $(\mathrm{X})$ foi limitado a N/X (N=72 o número total de plantas dos experimentos). Dessa forma, para $X=1$, 2, 3 e 4 , o número de parcelas foi, respectivamente, de 72, 36, 24 e 18 parcelas.

Para cada tipo de parcela simulada, foram realizadas análises considerando apenas as colheitas individuais e também as colheitas acumuladas. Para tanto, os grupos formados seguiram a sequência da divisão das colheitas obtidas pelos seus múltiplos nos diferentes experimentos. Assim, as múltiplas colheitas sucessivas foram agrupadas da seguinte maneira: a) um agrupamento duas a duas $\left(1^{\mathrm{a}}+2^{\mathrm{a}} ; 3^{\mathrm{a}}+4^{\mathrm{a}} ; \ldots ; 11^{\mathrm{a}}+12^{\mathrm{a}}\right)$, um agrupamento três a três $\left(1^{\mathrm{a}}+2^{\mathrm{a}}+3^{\mathrm{a}} ; 4^{\mathrm{a}}+5^{\mathrm{a}}+6^{\mathrm{a}} ; \ldots\right.$; $\left.10^{\mathrm{a}}+11^{\mathrm{a}}+12^{\mathrm{a}}\right)$, um agrupamento quatro a quatro $\left(1^{\mathrm{a}}+2^{\mathrm{a}}+3^{\mathrm{a}}+4^{\mathrm{a}} ; \ldots ; 9^{\mathrm{a}}+10^{\mathrm{a}}+11^{\mathrm{a}}+12^{\mathrm{a}}\right)$ e um agrupamento seis a seis $\left(1^{\mathrm{a}}+2^{\mathrm{a}}+3^{\mathrm{a}}+4^{\mathrm{a}}+5^{\mathrm{a}}+6^{\mathrm{a}} ; 7^{\mathrm{a}}+8^{\mathrm{a}}+9^{\mathrm{a}}+10^{\mathrm{a}}+11^{\mathrm{a}}+12^{\mathrm{a}}\right)$ no experimento de 2004; b) um agrupamento duas a duas $\left(1^{\mathrm{a}}+2^{\mathrm{a}} ; 3^{\mathrm{a}}+4^{\mathrm{a}} ; \ldots ; 9^{\mathrm{a}}+10^{\mathrm{a}}\right)$ e agrupamento cinco a cinco $\left(1^{\mathrm{a}}+2^{\mathrm{a}}+3^{\mathrm{a}}+4^{\mathrm{a}}+5^{\mathrm{a}} ; 6^{\mathrm{a}}+7^{\mathrm{a}}+8^{\mathrm{a}}+9^{\mathrm{a}}+10^{\mathrm{a}}\right)$ no experimento de 2005.

Para cada uma das colheitas individuais, das colheitas agrupadas e dos tamanhos de parcelas, foram estimadas a média da fitomassa de frutos das parcelas $\mathrm{M}(\mathrm{x})$ com X UB de tamanho, a Variância da fitomassa de frutos entre as parcelas $\mathrm{V}(\mathrm{x})$ de $\mathrm{X}$ unidades básicas de tamanho, a V1=variância da fitomassa de frutos entre as parcelas de uma unidade básica de tamanho, a VU $(\mathrm{X})=\mathrm{V}(\mathrm{x}) / \mathrm{X}^{2}$ variância da fitomassa de frutos por UB entre as parcelas de $\mathrm{X} U B, \mathrm{VR}(\mathrm{X})=\mathrm{V}(\mathrm{x}) / \mathrm{X}$, a variância reduzida e o $\mathrm{CV}(\mathrm{x})=$ Coeficiente de Variação entre as parcelas de $\mathrm{X}$ unidades básicas de tamanho. A partir dessas estimativas, foi calculado o índice de informação relativa (IR), pelo método da máxima informação relativa, atribuindo $100 \%$ às parcelas cujo tamanho fosse igual a uma UB. Para os demais tamanhos de parcela simulados, as IR foram obtidas pela expressão $\operatorname{IR}(\mathrm{x})=100 * \mathrm{~V} 1 / \mathrm{VR}(\mathrm{x})(\mathrm{KELLER}, 1949)$.
Em cada experimento, aplicou-se o teste de Bartlett (STEEL et al., 1997) entre as variâncias das colheitas individuais e agrupadas em cada tamanho de parcela simulado, para verificar a homogeneidade entre as variâncias dentro de cada colheita em diferentes tamanhos de parcela. Em todas as análises estatísticas foi adotado 5\% de probabilidade de erro.

\section{RESULTADOS E DISCUSSÃO}

A distribuição do percentual de plantas com frutos colhidos foi de 27,55 e 32,36\%, e a frequência de colheitas foi de 1,92 e 2,7 dias entre colheitas, respectivamente, para os anos de 2004 e 2005. Os valores de variância por UB apresentaram-se menores quando considerada uma planta nos diferentes agrupamentos (Tabelas 1 e 2). À medida que aumentou o número de plantas por parcela e, consequentemente, os valores das médias, ocorreu um acréscimo dos valores das variâncias mesmo em colheitas com frequência diferente (Tabelas 1 e 2). Com os agrupamentos, realizados principalmente com parcelas de uma planta em que as colheitas podem ou não ter frutos aptos a serem colhidos, foram identificadas três situações: duas colheitas sucessivas sem frutos, uma colheita com frutos e duas colheitas com frutos, interferindo diretamente na variância.

Apesar do incremento na estimativa da variância com o aumento do número de plantas por parcela e/ou agrupamento de colheitas, a partir de duas plantas por parcela com agrupamento de três em três colheitas (Tabela 1) e parcelas com uma planta agrupadas de duas em duas colheitas (Tabela 2), a homogeneidade das variâncias entre as colheitas ficou evidente. Esse resultado indica que, apesar do aumento no valor da variância, a partir do agrupamento entre colheitas sucessivas, a presença de parcelas sem frutos aptos a serem colhidos passa a ser reduzida, favorecendo assim que valores nulos não interferiram na estimativa da variância entre colheitas. Também MELLO et al. (2004) e LÚCIO et al. (2004) observaram que todas as variâncias por UB foram homogêneas para uma UB de tamanho, para a cultura da abobrinha e do pimentão, respectivamente, nos diferentes tamanhos e formas de parcelas simulados, independentemente da estação sazonal de cultivo.

O acréscimo no valor da variância pode ser explicado também pela relação existente entre essa estatística e a média, pois, de acordo com FEIJÓ et al. (2008), em colheitas de abobrinha italiana que apresentavam médias mais altas, as variâncias foram maiores. Esse comportamento também foi observado 
Tabela 1 - Variâncias da fitomassa de frutos $\left(\mathrm{g}^{2} \times 10^{3}\right)$ entre colheitas e entre os diferentes tamanhos de parcela simulados na mesma colheita, para abobrinha italiana cultivada em túnel plástico no ano de 2004.

\begin{tabular}{|c|c|c|c|c|}
\hline Colheitas & 1 & 2 & 3 & 4 \\
\hline 1 & $58,9^{\mathrm{HT}}$ & $\begin{array}{l}\text { as individ } \\
91,8^{\mathrm{HT}}\end{array}$ & $113,0^{\mathrm{HT}}$ & $174,9^{\mathrm{HT}}$ \\
\hline 2 & 48,8 & 125,5 & 195,3 & 271,6 \\
\hline 3 & 21,6 & 39,9 & 81,9 & 118,0 \\
\hline 4 & 22,9 & 39,7 & 55,9 & 72,5 \\
\hline 5 & 47,8 & 110,4 & 129,0 & 306,5 \\
\hline 6 & 45,8 & 106,5 & 167,3 & 239,6 \\
\hline 7 & 27,7 & 49,1 & 107,0 & 87,2 \\
\hline 8 & 87,5 & 204,4 & 333,2 & 342,3 \\
\hline 9 & 113,9 & 271,1 & 231,1 & 574,8 \\
\hline 10 & 32,6 & 82,4 & 140,3 & 212,2 \\
\hline 11 & 31,3 & 95,3 & 137,6 & 137,2 \\
\hline 12 & 40,8 & 91,0 & 137,2 & 219,3 \\
\hline Média & 48,3 & 108,9 & 152,4 & 229,7 \\
\hline CV\% & 57,0 & 62,1 & 48,5 & 60,0 \\
\hline 1 e 2 & $104,5^{\mathrm{HT}}$ & $214,2^{\mathrm{HT}}$ & $313,7^{\mathrm{HT}}$ & $364,9^{\mathrm{HT}}$ \\
\hline 3 е 4 & 33,9 & 47,9 & 102,0 & 158,7 \\
\hline 5 e 6 & 80,8 & 182,1 & 399,0 & 564,9 \\
\hline 7 e 8 & 127,8 & 271,4 & 516,0 & 468,5 \\
\hline 9 e 10 & 127,4 & 308,9 & 331,7 & 639,4 \\
\hline 11 e 12 & 62,6 & 163,4 & 260,1 & 283,2 \\
\hline Média & 89,5 & 198,0 & 320,4 & 413,3 \\
\hline CV\% & 41,9 & 46,3 & 43,3 & 43,5 \\
\hline 1,2 e 3 & $137,7^{\mathrm{HT}}$ & $\begin{array}{l}\text { grupadas tr } \\
321,4^{\mathrm{HM}}\end{array}$ & $449,0^{\mathrm{HM}}$ & $595,1^{\mathrm{HM}}$ \\
\hline 4,5 e 6 & 100,0 & 230,5 & 450,4 & 717,4 \\
\hline 7,8 е 9 & 209,5 & 432,1 & 726,6 & 804,3 \\
\hline 10,11 e 12 & 99,9 & 241,9 & 458,8 & 505,1 \\
\hline Média & 136,8 & 306,3 & 521,2 & 655,5 \\
\hline CV\% & 37,8 & 30,4 & 26,3 & 20,1 \\
\hline $1,2,3$ е 4 & $169,6^{\mathrm{HM}}$ & $\begin{array}{l}\text { padas quat } \\
354,9^{\mathrm{HM}}\end{array}$ & $536,0^{\mathrm{HT}}$ & $698,2^{\mathrm{HM}}$ \\
\hline $5,6,7$ e 8 & 215,1 & 537,8 & 1145,6 & 1110,2 \\
\hline $9,10,11$ e 12 & 191,7 & 470,2 & 726,7 & 845,6 \\
\hline Média & 202,7 & 498,5 & 921,9 & 734,6 \\
\hline CV\% & 14,3 & 25,8 & 36,4 & 16,9 \\
\hline $1,2,3,4,5$ e 6 & $295,4^{\mathrm{HM}}$ & $\begin{array}{l}\text { rupadas s } \\
743,0^{\mathrm{HM}}\end{array}$ & $1127,3^{\mathrm{HM}}$ & $1802,3^{\mathrm{HM}}$ \\
\hline $7,8,9,10,11$ e 12 & 271,3 & 627,1 & 1248,8 & 1282,4 \\
\hline Média & 283,4 & 685,0 & 1188,1 & 1542,3 \\
\hline CV\% & 6,0 & 12,0 & 7,2 & 23,8 \\
\hline
\end{tabular}

HM: Variâncias homogêneas entre colheitas;

HT: Variâncias heterogêneas entre colheitas pelo teste de Bartlett em nível de 5\% de probabilidade de erro.

CV\% - Coeficiente de variação entre as variâncias entre as colheitas individuais e agrupadas.

no presente trabalho, em que as estimativas das médias acompanharam os aumentos verificados para as variâncias estimadas. Dessa forma, o agrupamento de plantas para a redução da variabilidade é menos apropriada em comparação ao uso de apenas uma planta por parcela, quando se observa apenas a variância.

Na tabela 3, pode ser evidenciada acentuada redução dos valores do CV a partir do agrupamento de

Ciência Rural, v.40, n.2, fev, 2010. 
Tabela 2 - Variâncias da fitomassa de frutos $\left(\mathrm{g}^{2} \times 10^{3}\right)$ entre colheitas e entre os diferentes tamanhos de parcela simulados na mesma colheita, para abobrinha italiana cultivada em túnel plástico no ano de 2005.

\begin{tabular}{|c|c|c|c|c|}
\hline \multirow{2}{*}{ Colheitas } & \multicolumn{4}{|c|}{-Tamanho de parcelas (Plantas)- } \\
\hline & 1 & 2 & 3 & 4 \\
\hline 1 & $48,0^{\mathrm{HT}}$ & $66,7^{\mathrm{HT}}$ & $81,9^{\mathrm{HT}}$ & $67,9^{\mathrm{HT}}$ \\
\hline 2 & 48,0 & 78,6 & 78,5 & 210,6 \\
\hline 3 & 31,4 & 48,3 & 59,3 & 99,8 \\
\hline 4 & 51,4 & 68,6 & 77,9 & 191,9 \\
\hline 5 & 32,2 & 56,6 & 96,9 & 91,8 \\
\hline 6 & 44,2 & 70,6 & 110,6 & 89,1 \\
\hline 7 & 64,0 & 126,8 & 176,2 & 396,5 \\
\hline 8 & 49,4 & 62,8 & 74,9 & 59,2 \\
\hline 9 & 30,2 & 44,5 & 69,8 & 52,6 \\
\hline 10 & 22,3 & 55,5 & 106,2 & 183,7 \\
\hline Média & 42,1 & 67,9 & 93,2 & 144,3 \\
\hline $\mathrm{CV} \%$ & 30,0 & 34,1 & 35,7 & 73,4 \\
\hline 1 e 2 & $74,1^{\mathrm{HM}}$ & $162,3^{\mathrm{HM}}$ & $227,9^{\mathrm{HM}}$ & $386,7^{\mathrm{HT}}$ \\
\hline 3 e 4 & 78,1 & 166,3 & 155,4 & 456,9 \\
\hline 5 e 6 & 73,8 & 159,1 & 128,5 & 226,7 \\
\hline 7 e 8 & 53,9 & 124,1 & 246,6 & 266,9 \\
\hline 9 e 10 & 47,9 & 113,4 & 162,4 & 237,4 \\
\hline Média & 65,6 & 145,1 & 184,2 & 314,9 \\
\hline $\mathrm{CV} \%$ & 20,8 & 16,8 & 27,4 & 32,3 \\
\hline $1,2,3,4$ e 5 & $218,7^{\mathrm{HM}}$ & $\begin{array}{c}\text { rupadas ci } \\
540,8^{\mathrm{HM}}\end{array}$ & $554,1^{\mathrm{HM}}$ & $1445,0^{\mathrm{HM}}$ \\
\hline $6,7,8,9$ e10 & 148,8 & 421,3 & 769,7 & 809,5 \\
\hline Média & 183,7 & 481,0 & 661,9 & 1127,2 \\
\hline $\mathrm{CV} \%$ & 26,9 & 17,6 & 23,0 & 39,9 \\
\hline
\end{tabular}

HM: Variâncias homogêneas entre colheitas;

HT: Variâncias heterogêneas entre colheitas pelo teste de Bartlett em nível de 5\% de probabilidade de erro.

CV\% - Coeficiente de variação entre as variâncias entre as colheitas individuais e agrupadas.

colheitas, com as reduções sendo mais evidentes quando houve aumento do tamanho de parcela. O comportamento do CV foi similar nos experimentos realizados nos anos de 2004 e 2005. Porém, os valores do CV, no ano de 2005, foram sempre inferiores a 2004 e isto pode ser atribuído a menores variações climáticas ocorridas em 2005, concordando com LÚCIO et al. (2008) e CARPES et al. (2008). Esses autores afirmam que o comportamento das variâncias da fitomassa de frutos nos anos de 2004 e 2005 foram similares até a primeira metade do ciclo produtivo, mas na segunda metade a variância em 2004 foi significativamente superior à de 2005. Isso pode ser explicado em função de a temperatura média do ar de 18 a $25^{\circ} \mathrm{C}$ verão/ outono(V/O) e 15 a $23^{\circ} \mathrm{C}$ inverno/primavera(I/P) e o brilho solar de menos de uma a 8,5 horas (V/O) e de menos uma a 11,1 horas (I/P) terem sido semelhantes nas duas estações. MELLO et al. (2004) verificou que o cultivo sazonal outono/verão proporcionou valores de CV consideravelmente maiores em relação ao cultivo sazonal inverno/primavera, com essa variação atribuída às variações no brilho solar e nas temperaturas. OLIVEIRA (1995) alerta que há uma tendência em aumentar o coeficiente de variação com a redução do tamanho de parcela, o que dificulta a análise de dados provenientes de experimentos com parcelas de plantas individuais. Dessa forma, a utilização de mais plantas por parcela, além de favorecer a redução dos valores de CV, permite uma distribuição melhor dos valores ao longo das sucessivas colheitas.

Com os resultados apresentados para as variâncias e para o CV (Tabelas 1, 2 e 3), observa-se que as combinações de resultados mais apropriados aconteceram com parcelas de quatro plantas e colheitas agrupadas de quatro a quatro, para o ano de 2004, e 
Tabela 3 - Coeficiente de variação da fitomassa (\%) de frutos entre colheitas e entre os diferentes tamanhos de parcela simulados na mesma colheita, para abobrinha italiana cultivada em túnel plástico nos anos de 2004 e 2005.

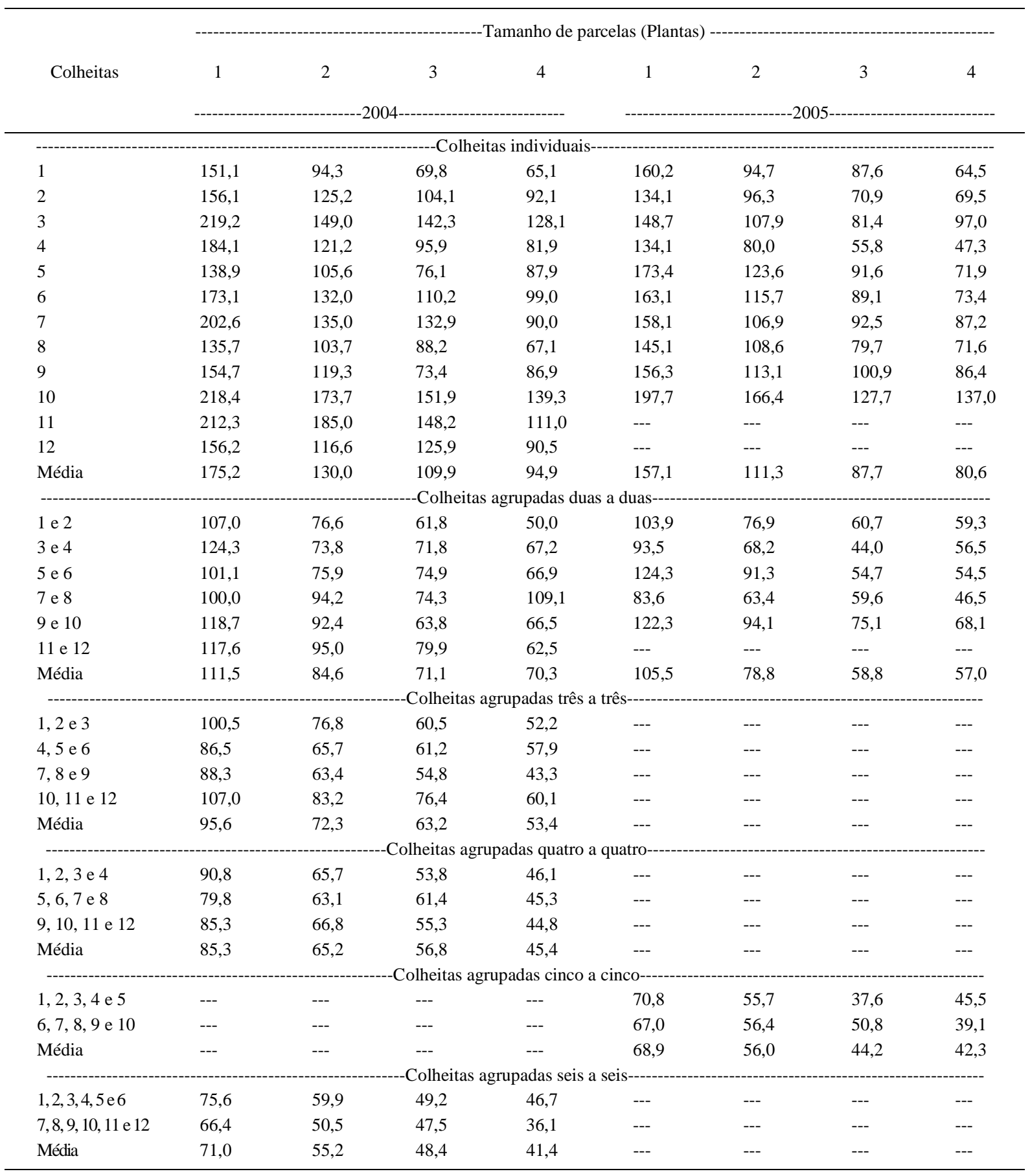

parcelas de três plantas e colheitas agrupadas de duas a duas, em 2005. Nesses casos as variâncias apresentaram menores estimativas e foram homogêneas entre colheitas com os CVs apresentando valores baixos, quando comparados com a maioria dos casos simulados.
Confirmando esses resultados, o índice de informação relativa (IR) apresentou decréscimos em suas estimativas ao serem agrupadas colheitas sucessivas (Tabela 4). Esses decréscimos, de forma geral, devem-se ao fato de que o agrupamento de colheitas e o aumento do tamanho de parcelas 
Tabela 4 - Índice de informação relativa da fitomassa (\%) de frutos entre colheitas e entre os diferentes tamanhos de parcela simulados na mesma colheita, para abobrinha italiana cultivada em túnel plástico nos anos de 2004 e 2005.

\begin{tabular}{|c|c|c|c|c|c|c|}
\hline \multirow[t]{2}{*}{ Colheitas } & 2 & 3 & 4 & 2 & 3 & 4 \\
\hline & \multicolumn{6}{|c|}{ 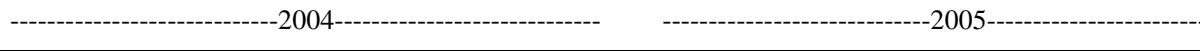 } \\
\hline \multicolumn{7}{|c|}{ 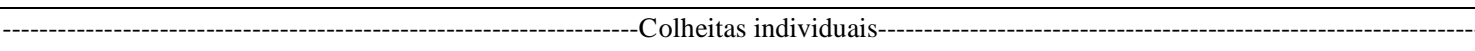 } \\
\hline 1 & 128,3 & 156,3 & 134,7 & 143,2 & 111,4 & 154,1 \\
\hline 2 & 77,8 & 74,9 & 71,8 & 96,9 & 119,2 & 93,0 \\
\hline 3 & 108,2 & 79,1 & 73,2 & 95,0 & 111,4 & 58,8 \\
\hline 4 & 115,3 & 122,8 & 126,2 & 140,5 & 192,3 & 200,9 \\
\hline 5 & 86,5 & 111,1 & 62,4 & 98,5 & 119,4 & 145,4 \\
\hline 6 & 86,0 & 82,1 & 76,5 & 99,5 & 111,8 & 123,6 \\
\hline 7 & 112,6 & 77,5 & 126,9 & 109,3 & 97,4 & 82,2 \\
\hline 8 & 85,6 & 78,8 & 102,3 & 89,3 & 110,5 & 102,7 \\
\hline 9 & 84,0 & 147,9 & 79,3 & 95,5 & 80,1 & 81,9 \\
\hline 10 & 79,9 & 69,7 & 69,4 & 70,6 & 79,9 & 52,0 \\
\hline 11 & 65,8 & 68,4 & 91,4 & --- & --- & --- \\
\hline 12 & 89,8 & 89,3 & 74,5 & --- & --- & --- \\
\hline Média & 93,3 & 96,5 & 90,7 & 103,8 & 113,4 & 109,5 \\
\hline CV\% & 19,8 & 31,8 & 28,1 & 21,5 & 27,6 & 42,5 \\
\hline 1 e 2 & 97,6 & 100,0 & $\begin{array}{r}\text { upadas } \\
114,6\end{array}$ & 91,3 & 97,6 & 76,7 \\
\hline 3 e 4 & 141,7 & 99,8 & 85,5 & 94,0 & 150,9 & 68,4 \\
\hline 5 e 6 & 88,8 & 60,8 & 57,2 & 92,8 & 172,3 & 130,2 \\
\hline 7 e 8 & 94,2 & 74,3 & 109,1 & 86,9 & 65,6 & 80,8 \\
\hline 9 e 10 & 82,5 & 115,2 & 79,7 & 84,4 & 88,4 & 80,7 \\
\hline 11 e 12 & 76,7 & 72,2 & 88,4 & --- & --- & --- \\
\hline Média & 96,9 & 87,0 & 89,1 & 89,9 & 115,0 & 87,3 \\
\hline CV\% & 24,0 & 24,1 & 23,4 & 4,5 & 39,0 & 28,0 \\
\hline 1,2 e 3 & 85,7 & \multicolumn{3}{|c|}{-----Colheitas agrupadas três a três---------- } & --- & --- \\
\hline 4,5 e 6 & 86,8 & 66,6 & 55,8 & --- & --- & --- \\
\hline 7, 8 e 9 & 97,0 & 86,5 & 104,2 & --- & --- & --- \\
\hline 10,11 e 12 & 82,6 & 65,3 & 79,1 & --- & --- & --- \\
\hline Média & 88,0 & 77,6 & 82,9 & --- & --- & --- \\
\hline $\mathrm{CV} \%$ & 7,1 & 17,6 & 25,1 & --- & -- & --- \\
\hline \multicolumn{7}{|c|}{----Colheitas agrupadas quatro a quatro----- } \\
\hline $5,6,7$ e 8 & 80,0 & 56,3 & 77,5 & --- & --- & --- \\
\hline $9,10,11$ e 12 & 81,6 & 79,2 & 90,7 & --- & --- & --- \\
\hline Média & 85,7 & 76,8 & 88,5 & --- & --- & --- \\
\hline CV\% & 10,0 & 25,3 & 11,3 & --- & --- & --- \\
\hline \multicolumn{6}{|c|}{----Colheitas agrupadas cinco a cinco--------- } & 60,5 \\
\hline $6,7,8,9$ e 10 & --- & --- & --- & 70,6 & 58,0 & 73,5 \\
\hline Média & --- & --- & --- & 75,8 & 88,2 & 67,0 \\
\hline $\mathrm{CV} \%$ & --- & --- & --- & 9,6 & 48,5 & 13,7 \\
\hline \multicolumn{7}{|c|}{-------Colheitas agrupadas seis a seis--------- } \\
\hline $7,8,9,10,11$ e 12 & 86,5 & 65,2 & 84,6 & --- & --- & --- \\
\hline Média & 83,0 & 71,9 & 75,1 & --- & --- & --- \\
\hline $\mathrm{CV} \%$ & 5,9 & 13,2 & 17,9 & --- & --- & --- \\
\hline
\end{tabular}

CV\% - Coeficiente de variação entre os índices de informação relativa entre as colheitas individuais e agrupadas. 
apresentaram, em média, valores de variância maiores em relação às colheitas individuais em tamanhos de parcela de uma planta. Quando agrupadas em duas, as colheitas de 2004 apresentaram redução do índice, em comparação com os agrupamentos de três plantas por parcela. Tal comportamento ficou mais acentuado em agrupamentos maiores de colheitas. Quatro plantas por parcela e agrupamentos de quatro a quatro colheitas, em 2004, e de três plantas por parcela com agrupamentos de duas a duas colheitas, em 2005, apresentaram valores da IR próximos a $100 \%$, pois reduziram a variabilidade produtiva de frutos de abobrinha italiana cultivada em ambiente protegido.

\section{CONCLUSÕES}

O aumento do tamanho da parcela e/ou do número de colheitas agrupadas aumenta as estimativas da variância da fitomassa de frutos entre colheitas de abobrinha italiana. As variâncias tornam-se homogêneas a partir do agrupamento das colheitas. Parcelas com quatro plantas e agrupamento de quatro a quatro colheitas sucessivas reduzem a variabilidade.

\section{AGRADECIMENTOS}

Ao Conselho Nacional de Desenvolvimento Científico e Tecnológico (CNPq), pelo auxílio financeiro e pelas bolsas de iniciação científica e de produtividade em pesquisa.

\section{REFERÊNCIAS}

CAMARGO. L.S. As hortaliças e seu cultivo. Campinas: Fundação Cargill, 1981. 321p.

CARPES, R.H. et al. Ausência de frutos colhidos e suas interferências nas estimativas da fitomassa de frutos de abobrinha italiana cultivada em diferentes sistemas de irrigação. Revista Ceres, Viçosa, v.55, n.6, p.590-595, 2008. Disponível em: <http://www.ceres.ufv.br/CERES/revistas/V55N006P37108.pdf>. Acesso em: 02 de fev. 2009.

CERMEÑO, Z.S. Estufas - instalações e manejo. Lisboa: Litexa, 1990. 355p.

FEIJÓ, S. et al. Heterogeneity index of zucchini yield on a protected environment and experimental planning. Horticultura Brasileira, Brasília, v.26, n.1, p.35-39, 2008. Disponível em: <http://www.scielo.br/pdf/hb/v26n1/ a07v26n1.pdf $>$. Acesso em: 30 jun. 2009. doi: 10.1590/S010205362008000100007 .

FILGUEIRA, F.A.R. Novo manual de olericultura: tecnologia moderna na produção e comercialização de hortaliças. Viçosa: UFV, 2000. 402p.

KELLER, K. Uniformity trials on hops, Humulus lupulus L., for increasing the precision of field experiments. Agronomy Journal, Madison, v.41, n.8, p.389-392. 1949. Disponível em: <http://agron.scijournals.org/cgi/reprint/41/8/389>. Acesso em: 06 jan. 2008
LOPES, S.J. et al. Técnicas experimentais para tomateiro tipo salada sob estufas plásticas. Ciência Rural, Santa Maria, v.28, n.2, p.193-197, 1998. Disponível em: <http:// www.scielo.br/pdf/cr/v28n2/a02v28n2.pdf>. Acesso em: 29 nov. 2008. doi: 10.1590/S0103-84781998000200002.

LORENTZ, L.H. et al. Variação temporal do tamanho de amostra para experimentos em estufa plástica. Ciência Rural, Santa Maria, v.34, n.4, p.1043-1049, 2004. Disponível em: <http://www.scielo.br/pdf/cr/v34n4/a12v34n4.pdf>. Acesso em: 29 nov. 2008. doi: 10.1590/S0103-84782004000400012.

LORENTZ, L.H. et al. Variabilidade da produção de frutos de pimentão em estufa plástica. Ciência Rural, Santa Maria, v.35, n.2, p.316-323, 2005. Disponível em: <http:// www.scielo.br/pdf/cr/v35n2/a11v35n2.pdf $>$. Acesso em: 29 nov. 2008. doi: 10.1590/S0103-84782005000200011.

LÚCIO, A.D. et al. Variância e média da massa de frutos de abobrinha-italiana em múltiplas colheitas. Horticultura Brasileira, Brasília, v.26, n.3, p.335-341, 2008. Disponível em: <http://www.scielo.br/pdf/hb/v26n3/09.pdf>. Acesso em: 19 jul. 2009. doi: 10.1590/S0102-05362008000300009.

LÚCIO, A.D. et al. Variação temporal da produção de pimentão influenciada pela posição e características morfológicas das plantas em ambiente protegido. Horticultura Brasileira, Brasília, v.24, n.1, p.31-35, 2006. Disponível em: <http:// www.scielo.br/pdf/hb/v24n1/a07v24n1.pdf>. Acesso em: 19 jul. 2009. doi: 10.1590/S0102-05362006000100007.

LÚCIO, A.D. et al. Estimativa de parâmetros para o planejamento de experimentos com a cultura do pimentão em área restrita. Horticultura Brasileira, Brasília, v.22, n.4, p.66-770, 2004. Disponível em: <http://www.scielo.br/pdf/hb/ v22n4/23192.pdf $>$. Acesso em: 19 jul. 2009. doi: 10.1590/ S0102-05362004000400020.

MARODIM, V.S. et al. Delineamento experimental e tamanho de amostra para alface cultivada em hidroponia. Ciência Rural, Santa Maria, v.30, n.5, p.779-781, 2000. Disponível em: <http://www.scielo.br/pdf/cr/v30n5/a06v30n5.pdf>. Acesso em: 29 nov. 2008. doi: 10.1590/S0103-84782000000500006.

MELLO, R.M. et al. Size and form of plots for the culture of the italian pumpkin in plastic greenhouse. Scientia Agricola, Piracicaba, v.61, n.4, p.457-461, 2004. Disponível em: <http:/ /www.scielo.br/pdf/sa/v61n4/22165.pdf>. Acesso em: 01 abr. 2008. doi: 10.1590/S0103-90162004000400017.

OLIVEIRA, M.R.V. O emprego de casas de vegetação no Brasil: vantagens e desvantagens. Pesquisa Agropecuária Brasileira, Brasília, v.30, n.8, p.1049-1060, 1995. Disponível em: <http://webnotes.sct.embrapa.br/pab/pab.nsf/FrAnual>. Acesso em: 15 jun. 2009.

SOUZA, M.F. et al. Tamanho da amostra para peso da massa de frutos, na cultura da abóbora italiana em estufa plástica. Revista Brasileira de Agrociência, Pelotas, v.8, n.2, p.131-136, 2002. Disponível em <http://www.ufpel.tche.br/faem/agrociencia/ v8n2/artigo07.pdf>. Acesso em: 17 mai 2008.

STEEL, R.G.D. et al. Principles and procedures of statistics: a biometrical approach. 3.ed. New York: McGraw-Hill, 1997. 666p.

STORCK, L. et. al. Experimentação vegetal. Santa Maria: UFSM, 2006. 198p. 